\title{
Interview
}

\section{An interview with Dr. Martin Lamb on research in English language learning and teaching}

\author{
Berta Torras-Vila \\ Universitat Autònoma de Barcelona
}

Text received 17 January 2016; final version 29 January 2016

DOI: http://dx.doi.org/10.5565/rev/jt13.664

\begin{abstract}
Dr. Martin Lamb is Senior Lecturer in TESOL at the School of Education, University of Leeds (United Kingdom). His research interests include all aspects of language learner motivation, but especially how it relates to identity, social relations and autonomous learning behaviour, and how it can be developed through good teaching. Most of Dr. Lamb's research has been based in Indonesia, trying to understand the various motivational and social factors that contribute to the successful learning of English. His most recent project, in collaboration with Dr. Martin Wedell, was a British Council-funded investigation into "inspiring" English teaching in state schools in China and Indonesia.

He has taught English as a Foreign Language in Sweden, Saudi Arabia, Indonesia and Bulgaria and has also worked as a teacher educator on development projects in the latter two countries. At Leeds he is Co-ordinator of the MA TESOL programme and teaches a range of undergraduate and postgraduate courses. His Masters modules specifically focus on L2 speaking, assessing language learning, and developing practical teaching skills. At an undergraduate level, he teaches modules on "Education in a multilingual world" and "Globalization, identity and English language education". He is also a personal and academic tutor to international MA students.

The interview published in this issue was conducted in the autumn of 2015, while the author was participating in a research stay for her doctoral thesis at the University of Leeds. In this interview, several issues on English language education are discussed and presented from the standpoint of an SLA research expert.
\end{abstract}

\section{Interview}

Interviewer: You have extensive experience teaching English in different contexts and countries (Sweden, Saudi Arabia, Indonesia and Bulgaria). What do you think language teachers can gain from getting involved in research and what could be done to bring teachers and educational research closer together? 
Martin Lamb: Well, this a very big question and one that is being debated at the moment quite vigorously. For example, there is a recent discussion in the ELT Journal about this, an argument between Simon Borg, he is a Leeds lecturer, who has written a book on teacher research, and Richard Smith, in Warwick, who has a different view. In the end it all depends really on what one means by teachers engaging with research. We can be fairly sure that at the moment teachers do not engage very much with research at the moment. Do you know Emma Marsden from York? She has done a study of British language teachers, seeing how much they read research and it seems like the answer is very little. So there are two aspects to this issue. First of all there is teachers engaging with research that is written up, so looking at the findings of research and trying to learn from that, to inform their own teaching; and, secondly, there is the notion of teachers doing research themselves. In regard to the first, teachers reading research, it seems like not much is done and I think more should be done to try to make our research more accessible for teachers. As it happens, I am developing a research project proposal right now to try to see how academic motivation theory, which is a very well developed field, could be made more accessible and usable for teachers.

Interviewer: Spain has a reputation for having poor results in foreign language learning. From an observer's point of view, how could this be improved and what factors should be taken into consideration?

Martin Lamb: Well, I have never lived in Spain, I have never worked there, so I am hesitant to give my opinions, but I would guess that a reason that Spain has this reputation is party because of the vitality of Spanish as a world language, in that it is the dominant language in Latin America, it is a fast rising language even in North America, and it is predicted to even overtake English in number of native speakers in North America. It is partly because of the vitality of Spanish culture and language that Spain and Spanish people have felt no need to learn English, but I do think it is changing, and my impression is that Spain, at least the middle classes, or the professional classes, in Spain, realized that to engage with the rest of the world, even just to engage with Europe, requires learning English particularly, so things seem to be changing. Spain is in the forefront of innovation when it comes to CLIL, teaching language through using it as the medium of instruction in other subjects, and from what I have read it is... there are problems, of course, but it is making good progress. The reason why something like CLIL may be necessary is because in countries like Spain, I would guess, learners do not get that much exposure to English outside the classroom, unlike in northern 
Europe, in places like Holland, Germany, Scandinavia, where there is much more English in the environment. Television programmes are not dubbed into the $\mathrm{L} 1 \ldots$ there is that much more attention given perhaps to Anglophone culture in northern Europe. So in countries like Spain it is really essential to try to maximize the amount of exposure that learners get so that they have a sense of making progress in the language, because ultimately nothing is more demotivating than studying a subject at school and just not feeling you are getting anywhere, not feeling you are making any progress and not really developing any skills.

Interviewer: What kind of potential do you think research on motivation and identity has for developing new strategies to teach English?

Martin Lamb: As I was saying I think academic motivation theory is very well developed, there are all these different theories... Expectancy Value Theory, Achievement Theory, Goal Theory, Attribution Theory... in language learning we have things like Gardner's Socioeducational model, we have Dörnyei's L2 Motivational Self System and so on. Theory is really quite well developed, but application of it is very underdeveloped, and we need more research linking this theory to practice, I think. One line of research, which is very interesting and promising, is the Motivational Strategies research. The first stage of the research was asking teachers through surveys what they believed about motivation and how they motivate their own learners, but now we have got research which is training teachers to use certain strategies and then monitoring their teaching and seeing whether it does have an effect on learner motivation. I think this kind of research, looking at interventions where teachers use some strategies to deliver and motivate their learners and seeing whether they work or not is a promising line of research. However, I do not think it is enough because a lot of motivation to learn language in a classroom comes from other aspects of teacher behaviour. I mean, obviously there is a lot connected to the language in general and learners' own visions of their future selves, and so on, which I think is important, but a lot of learner motivation comes from the teachers' own attitudes and the teachers' unconscious behaviour. If the teacher is enthusiastic about the subject, and this applies not just to language, but to any subject, the learners pick up on that. And vice versa. If the teacher does not show enthusiasm then how can they expect the learners to get enthusiastic about it? So things like the relationship that the teacher develops with the learners, whether the teacher shows that they care for the learners and whether they are learning or not, and the teachers' enthusiasm for the subject... I think 
these more sort of nebulous things are just as important for motivation and we need more research on those aspects of the classroom.

Interviewer: Could you tell us a little about your extensive research on motivation to learn English? To what extent does it affect a learner's process? What challenges does it embed?

Martin Lamb: My modest, I think, research, not extensive, has mainly been about Indonesian learners of English and just because that is where I spent many years teaching English. I always believed that there was a problem with motivation in Indonesia, not that learners were not motivated to learn English, they all are, but it does not seem to translate into effort to learn. There is a sort of barrier between desire to learn the language, desire for the language, and the willingness to put effort, sustained effort into learning because obviously, success only comes through sustained effort over many years. So one of the things I have been doing in Indonesia is following, tracking a number of learners, from 2002, who were the original participants in my doctoral research, through to this year - I am still in touch with many of them - they were aged 11 or 12 and now they are in their early twenties and it has been fascinating to see those who I chose in my original study as motivated learners, highly motivated learners, have really succeeded well in learning the language, and they are all now using it in their lives and in their work, to some degree, whereas those who I identified as less motivated, back in 2002, have made much less progress. They still desire to learn English but they, for whatever reason, they have not really achieved any mastery over the language, and they have ended up very frustrated really. If anything, their motivation has grown over that time, but they have not been able to learn.

Interviewer: English has become a "global language". Taking into account this reality, what factors do you consider as positive and negative and what challenges does this reality imply?

Martin Lamb: Well, I think it is great that there is a global language now, I mean, in this era of globalization where national borders are coming down and we are all communicating across borders, we obviously need a global language, and we, in the Anglophone countries are just very fortunate that it is our language. The downside of that, of course, is that for us, our young people do not really see any need to learn another language, so there are some kind of negative attitudes in the British education system towards the teaching and learning of foreign languages, and we will suffer from that in the future, because every society needs multilingual people. Just because there is a global language does not mean that we can rely on other people 
speaking languages. If we want to sell our products to other countries, we cannot expect our customers necessarily to speak our language. So yes it is good that there is a global language, we are lucky that it is English, but I also think that bilingualism and multilingualism are really positive on an individual and on a societal level. Monolingual countries like Britain and America, we need to work especially hard, to try to develop a multilingual culture in the education system.

Interviewer: You have also done research on "inspiring" teachers in a specific context (Indonesia). In your article "Cultural contrasts and commonalities in inspiring language teaching", you look at these issues taking into account the Indonesian context and the Chinese context. How would you apply your findings and discussion in that study to a broader context?

Martin Lamb: I think that the big lesson that we learned from that project was that learner motivation is very closely connected with teacher motivation, because all the inspiring teachers who we identified, in Indonesia and in China, they taught in very different ways. There were many different ways to be an inspiring teacher in classroom, these teachers were different in personality, they were different in the methods they used in the classroom and obviously that reflected the educational cultures, which are very different in Indonesia and China, despite them being Asian countries, they are very different. However, what all these teachers did have in common was that they were committed, enthusiastic teachers... and as I was saying before, the learners pick up on that, and that is at the heart of successful teaching, certainly successful motivating teaching. You have to really want to teach to be successful as a teacher I think. I mean I am sure many teachers get by, just as learners get by, they may pass, get the grades they want in the exams, and the teachers teach the courses, and so on, but truly inspiring teaching, the kind that persuades learners to carry on studying something once the course is finished, or inspires them to learn at home at the weekend or whatever, that is truly motivating teaching, and I think that comes as much from the teacher commitment and teacher motivation, as it does from particular methods.

Interviewer: Could you tell us about what you are currently working on?

Martin Lamb: I am trying to extend that research to two other contexts. I have a colleague in India who is trying to collect data about inspiring teachers of English in India, and someone else in Brazil, although it is quite challenging to get good quality data on this topic. Another 
project I am involved in is related to IELTS exam. It is a qualitative study, a case study of learners preparing for the IELTS exam, trying to see a relationship between the progress they make on the IELTS exam and the nature of their motivation to do the exam. Obviously it is a big underexplored issue, how in this era many education systems around the world are introducing more forms of assessment and high-stakes assessment, as all part of a part of accountability agenda, so learners in Britain... there is a big debate about when learners should stop being tested at five, seven or eleven... how often they should be tested and so on. We need to know what is the motivational effect of these tests. Many would argue that they are demotivating because they introduce a kind of extrinsic motive for studying and they force teachers to teach in certain ways that make the subject less interesting and motivating; but on the other hand, there is no doubt that short-term goals like passing a test can provide short-term motivation as well. I think it is an interesting issue that can be explored. And the other thing that I am currently working on, well, just beginning to work on, really, as I mentioned before, is a possible research proposal for looking at ways of helping language teachers in the UK to use motivation theory to adapt their teaching in order to strengthen the motivation of their pupils learning French or German or indeed Spanish in English schools, but it is still in the early stages.

Interviewer: Thank you very much.

\section{References}

Lamb, M., \& Wedell, M. (2015). Cultural contrasts and commonalities in inspiring language teaching. Language Teaching Research, 19 (2), 207-224.

Author information: Berta Torras-Vila is a primary school teacher. She holds a Master in The Acquisition of English and Intercultural Communication (Universitat Autònoma de Barcelona) and a Master in TESOL/Applied Linguistics (University of Bristol). She is currently completing her $\mathrm{PhD}$ on the role of student-teachers' imagined identities in their investments in English in the context of the English-Medium Primary Education Bachelor's Degree offered by the UAB.

Email: berta.torras@uab.cat

To cite this article:

Torras-Vila, B. (2016). An interview with Dr. Martin Lamb on research in English language learning and teaching. Bellaterra Journal of Teaching \& Learning Language \& Literature, 9(1), 89-94. DOI:

http://dx.doi.org/10.5565/rev/jtl3.664 